Interfacial optimization of tungsten fibre-reinforced copper for hightemperature heat sink material for fusion application

A. Herrmann, K. Schmid, M. Balden, H. Bolt

Max Planck Institute for Plasma Physics, EURATOM Association, Garching, Germany

*Corresponding author: Aurelia Herrmann

Phone: +498932 99-1790

Fax: +49 8932 99-12 12

aurelia.herrmann@ipp.mpg.de 


\title{
Interfacial optimization of tungsten fibre-reinforced copper for high- temperature heat sink material for fusion application
}

\author{
A. Herrmann, K. Schmid, M. Balden, H. Bolt \\ Max Planck Institute for Plasma Physics, EURATOM Association, Garching, Germany
}

\begin{abstract}
$\mathrm{W}$ fibre-reinforced $\mathrm{Cu}$ shows great promise to improve the mechanical performance at high temperatures compared to conventional Cu-based alloys. Focus was placed on the optimization of the interface to achieve an enhanced adhesion between $\mathrm{W}$ fibre and $\mathrm{Cu}$ matrix. The interfacial properties were investigated through pull-out measurements of single matrix-coated fibres for different interfacial concepts. The interfacial adhesion of $\mathrm{W}$ and $\mathrm{Cu}$ is determined solely through mechanical interlocking. Interdiffusion and segregations experiment showed that there are no interface reactions between $\mathrm{W}$ and $\mathrm{Cu}$ at elevated temperatures. From the investigated interfacial concepts, a stepwise graded transition interface with additional heat treatment was found to achieve the highest interfacial shear strength. The thermal stability of the MMC in thermal cycling tests can be assured by depositing a stepwise graded transition between $\mathrm{W}$ fibre and $\mathrm{Cu}$ matrix.
\end{abstract}

\section{Introduction}

In future fusion reactors like DEMO the fusion plasma leads to a heat flux of up to $20 \mathrm{MW} / \mathrm{m}^{2}$ in the divertor region $[1,2]$. The heat has to be removed efficiently from the plasma facing material (PFM) through the $\mathrm{Cu}$-based heat sink to the cooling channels. According to the 
power plant conceptual study (model A) it is desired to increase the cooling water temperature to at least $300^{\circ} \mathrm{C}$ for efficient energy production [3]. Depending on the divertor design, this will lead to high temperatures of up to $550^{\circ} \mathrm{C}$ at the interface between PFM (W, C) and heat sink material $(\mathrm{Cu}, \mathrm{CuCrZr})[4]$. The mechanical properties of the current $\mathrm{Cu}$-based material at this high temperature are insufficient. Additionally, due to the temperature gradient and different coefficients of thermal expansion (CTE) of $\mathrm{W}$ and $\mathrm{Cu}$-based materials, high stresses occur at the interface of PFM and the heat sink material [5]. Metal matrix composites (MMC), like W fibre-reinforced copper, has the potential to strengthen this zone. The fibres will contribute the strength of the composite at high temperatures and $\mathrm{Cu}$ will provide the required thermal conductivity.

A stable interface between the $\mathrm{W}$ fibre and the $\mathrm{Cu}$ matrix is a basic requirement for good mechanical properties of the MMC. Therefore, this work aims to optimize the interface to achieve an enhanced adhesion between $\mathrm{W}$ fibre and $\mathrm{Cu}$ matrix. The interfacial properties were investigated through pull-out measurements of single matrix-coated fibres for four different interfacial concepts: 1) direct interface between $\mathrm{W}$ fibre and the electroplated $\mathrm{Cu}$ matrix without deposited interlayer; 2) W fibres deposited with a thin $\mathrm{Cu}$ interlayer by magnetron sputter deposition and subsequent electroplating of the $\mathrm{Cu}$ matrix; 3) W fibre deposited with a stepwise graded transition between $\mathrm{W}$ fibre and the electroplated $\mathrm{Cu}$ matrix by magnetron sputter deposition; and 4) same as 3) plus additional heat treatment at $800^{\circ} \mathrm{C}$.

To understand the reactions between $\mathrm{W}$ and $\mathrm{Cu}$ at the interface during the synthesis process of the MMC or during its use in the divertor, dedicated interdiffusion and segregation experiments utilizing Rutherford Backscattering Spectrometry (RBS) are performed.

As the $\mathrm{CTE}$ of the $\mathrm{W}$ fibre and the $\mathrm{Cu}$ matrix differs, thermal cycling test on multi fibre MMC were performed to investigate the thermal stability of the compound. The MMC with 
interfacial concept 2 , thin $\mathrm{Cu}$ interlayer between fibre and matrix, and the MMC with interfacial concept 3 , stepwise graded transition between fibre and matrix, were compared. 


\section{Material and experimental}

\subsection{Interdiffusion and segregation experiments}

To understand the reactions between $\mathrm{W}$ and $\mathrm{Cu}$ at elevated temperatures, the type of bonding between the $\mathrm{W}$ fibre and the $\mathrm{Cu}$ matrix must be identified. The binary phase diagram [6] suggests that no chemical alloying of $\mathrm{Cu}$ and $\mathrm{W}$ occur independent of temperature. This was verified in interdiffusion experiments where $\mathrm{W} / \mathrm{Cu}$ diffusion couples were tempered at $500^{\circ} \mathrm{C}$, $650^{\circ} \mathrm{C}, 800^{\circ} \mathrm{C}$ and $900^{\circ} \mathrm{C}$. The diffusion couples were made from high-purity $\mathrm{Cu}$ substrates (Goodfellow) on which a 500nm W layer was deposited by magnetron sputter deposition. After tempering the resulting $\mathrm{Cu}$ and $\mathrm{W}$ depth profiles were measured using Rutherford Backscattering Spectrometry (RBS). Due to the insolubility of $\mathrm{Cu}$ and W [7], segregation experiments are performed to investigate the stability of the stepwise graded transition layers (Concept 3) at elevated temperatures. For the segregation experiment a stepwise graded $\mathrm{W} / \mathrm{Cu}$ transition was deposited on a $\mathrm{W}$ substrate. The $\mathrm{Cu}$ concentration is thereby increased in approximately $25 \%$ steps from $100 \% \mathrm{~W}$ to $100 \% \mathrm{Cu}$. This sample was tempered at $650^{\circ} \mathrm{C}$ for 60 minutes and the resulting $\mathrm{Cu}$ and $\mathrm{W}$ depth profiles were measured using (RBS).

For both experiments the RBS measurements were performed using a $6 \mathrm{MeV}^{4} \mathrm{He}^{2+}$ ion beam and a scattering angle of $165^{\circ}$. The $\mathrm{Cu}$ and $\mathrm{W}$ depth profiles were extracted from the measured spectra using the SIMNRA program [8].

\subsection{Single matrix-coated fibres for pull-out measurements}

For the mechanical characterization of the interface between the fibre and matrix, pull-out tests on single matrix-coated $\mathrm{W}$ fibres were performed. W fibres (OSRAM) with a diameter 
of $100 \mu \mathrm{m}$ were used for the single matrix-coated fibres and for long-fibre reinforcement of the $\mathrm{Cu}$ matrix. The as-received fibres were cleaned with aceton and isopropanol. The $\mathrm{W}$ fibres were fixed on a $\mathrm{Cu}$ frame and positioned perpendicular to the sample holder plate in the magnetron sputter deposition machine. The surface of the $\mathrm{W}$ fibres was cleaned by Ar ion sputtering for $2 \mathrm{~min}$ at $100 \mathrm{~W}$. For interface concept $2 \mathrm{a} \mathrm{Cu}$ coating of $500 \mathrm{~nm}$ was deposited using only the $\mathrm{Cu}$ cathode. For the interface concepts 3 and 4 a stepwise graded transition coating from $\mathrm{W}$ to $\mathrm{Cu}$ of approximate $800 \mathrm{~nm}$ was deposited by varying the power to the $\mathrm{Cu}$ and $\mathrm{W}$ electrode. The $\mathrm{Cu}$ concentration is thereby increased in approximately $25 \%$ steps from the $\mathrm{W}$ fibre to the $\mathrm{Cu}$ matrix. All $\mathrm{W}$ fibres were electroplated during $22 \mathrm{~h}$ at room temperature in $\mathrm{CuSO}_{4}$ bath to obtain an adequate matrix thickness $(\sim 1 \mathrm{~mm})$. After deposition, the fibres were heat-treated at $550^{\circ} \mathrm{C}$ for $1 \mathrm{~h}$ with a slow heating rate of $20^{\circ} \mathrm{C} / \mathrm{h}$ to avoid the formation of pores by outgassing of hydrogen and oxygen contained in a electroplated layer. The length of the electroplated $\mathrm{Cu}$ matrix was varied by cutting to obtain embedded fibres with various lengths between $0.5 \mathrm{~mm}$ and $3 \mathrm{~mm}$.

A universal test machine was used to pull the single matrix-coated fibres out of the matrix. During the pull-out the displacement and the resulting load were acquired continuously. From this raw data the $P_{d}$ value, the first local maximum peak of the load-displacement curve indicating the onset of debonding, and the $\mathrm{P}_{\mathrm{fr}}$ value, the load required to overcome the pullout friction, manifesting in oscillating of the curve, were determined. The values $\mathrm{P}_{\mathrm{d}}$ and $\mathrm{P}_{\mathrm{fr}}$ as function of the embedded length serve as data which will be fitted with formulas taken from [9] to obtain the two characteristic interfacial properties: the interfacial shear strength $\tau_{\mathrm{d}}$ and interfacial friction stress $\tau_{\mathrm{f}}$. The interfacial shear strength $\tau_{\mathrm{d}}$ is defined as the maximum shear stress encountered at the interface of fibre and matrix just prior to the onset of debonding [10]. The interfacial friction stress $\tau_{\mathrm{f}}$ causes the reactive force during fibre slip opposite to the moving direction [10]. 


\subsection{Multi fibre MMC for thermal stability testing}

To investigate the influence of the CTE mismatch of $\mathrm{W}$ fibre and $\mathrm{Cu}$ matrix on the microstructure during heat treatment, thermal cycling test were performed on MMCs with the interfacial concept 2 and 3. The synthesis of the multi fibre MMCs for thermal stability testing was performed similar to the single matrix-coated fibre. The thickness of the electroplated $\mathrm{Cu}$ layer of the coated fibres defines the fibre volume content in the composite: to obtain a fibre volume fraction of $20 \%$, the pre-coated fibres were electroplated with a $\sim 60$ $\mu \mathrm{m}$ thick $\mathrm{Cu}$ layer within $73 \mathrm{~min}$ instead of $22 \mathrm{~h}$ as for the single coated fibre synthesis. After the deposition, the fibres were slowly outgassed as the single fibres. In the last step, the coated and heat-treated single fibres were packed in a $\mathrm{Cu}$ capsule and consolidated by hotisostatic pressing at $650^{\circ} \mathrm{C}$ with a pressure of $100 \mathrm{MPa}$ for $30 \mathrm{~min}$. The resulting $\mathrm{MMC}$ shows a homogeneous fibre distribution. Thin discs of $1 \mathrm{~mm}$ were cut out of the MMC, polished on both sides and characterized by SEM before and after thermal cycling. For thermal stability testing, the discs were cycled 120 times between $350^{\circ} \mathrm{C}-550^{\circ} \mathrm{C}$ with a rate of $\pm 10 \mathrm{~K} / \mathrm{min}$.

\section{Results and discussion}

\subsection{Interdiffusion and segregation experiments}

The RBS profiles of $\mathrm{W}$ and $\mathrm{Cu}$ after tempering the $\mathrm{W} / \mathrm{Cu}$ diffusion couples are shown in Fig. 1. The curves show the $\mathrm{W}$ and $\mathrm{Cu}$ peak. By investigating the left edge of the $\mathrm{W}$ peak a slightly shift of the curves at different temperatures is observed. This results from the thickness variation of the measured samples caused by the inhomogeneous magnetron sputter 
deposition process of the $\mathrm{Cu}$ substrates. As there is no change in the slopes of the different curves, an interdiffusion between $\mathrm{W}$ and $\mathrm{Cu}$ can be ruled out.

The result of the segregation experiment is depicted in Fig. 2 which shows the RBS spectra of the stepwise graded transition before and after heating. The curves show the $\mathrm{W}$ and $\mathrm{Cu}$ peak with the different concentration steps at the specific energies. As the steps of the heat and the unheated depth profiles remain constant and no peak width variations are observed, a segregation of $\mathrm{W}$ and $\mathrm{Cu}$ can be ruled out.

\subsection{Pull-out measurements}

The mechanical interface properties are described by the interfacial shear strength $\tau_{\mathrm{d}}$ and the interfacial friction stress $\tau_{\mathrm{f}}$ calculated from single matrix-coated fibre pull-out tests. Solely the $\tau_{\mathrm{d}}$ results of the four interfacial concepts will be discussed and are shown in Fig. 3. The determined interfacial shear strength value of the interfacial concept 1 indicates a poor mechanical interlocking in the $\mathrm{Cu}$ matrix. Interfacial concept 2 does not indicate significant increase of interfacial shear strength. In contrast, interfacial concept 3 shows a 3 fold higher interfacial shear strength than concept 1 and 2. For Interfacial concept 4, the additional heat treatment has a dramatic influence on the interfacial shear strength: A 6 fold increase in shear strength compared to concept 1 can be achieved which indicates a strong bonding between fibre and copper. From performed surface diffusion simulations it is known that at $800^{\circ} \mathrm{C}$ surface diffusion occurs between $\mathrm{W}$ and $\mathrm{W}$. It can be assumed that the surface diffusion between the grains of the $\mathrm{W}$ fibre and the grains of the $\mathrm{W}$ layer of the graded transition at $800^{\circ} \mathrm{C}$ is responsible for the strong bonding.

As it can be seen from the SEM images (see Fig. 4), the surfaces of the pulled fibres vary. Fig. $4 \mathrm{a}$ ) and $4 \mathrm{~b}$ ), showing the pulled fibres of interfacial concept 1 and 2 , indicate no $\mathrm{Cu}$ 
matrix residues on the $\mathrm{W}$ fibre surface. The determined interfacial shear strength value indicates a poor mechanical interlocking. Fig. 4c), showing the pulled fibre surface with the stepwise graded transition interlayer, shows many small amounts of $\mathrm{Cu}$ residues on the $\mathrm{W}$ fibre surface. This indicates a good bonding between fibre and transition layer and correlates to the higher interfacial shear strength. The SEM image of the slipped fibre of the graded transition interfacial system plus additional heat treatment (Fig. 4d)) shows large area of $\mathrm{W} / \mathrm{Cu}$ graded layer residue on $\mathrm{W}$ fibre surface. This system has the highest interfacial properties which indicate a strong bonding between fibre and matrix.

\subsection{Thermal cycling for thermal stability testing}

The SEM images (Fig. 5) show the two investigated MMC discs after the thermal cycling test. The $\mathrm{W}$ fibres of the MMC with the interfacial concept 2 debond during thermal cycling which indicates a weak interfacial adhesion (see Fig. 5a) and its magnification 5b)). In contrast the fibres with interface concept 3, depicted in Figs. 5c) and 5d), show that the fibres bond to the matrix and that the displacements occur solely at the $\mathrm{Cu}$ grain boundaries. This indicates a strong bonding between fibre and matrix. It can be assumed that the graded transition between $\mathrm{W}$ fibre and $\mathrm{Cu}$ matrix acts as stepwise adaptation of CTE mismatch between $\mathrm{W}$ fibre and $\mathrm{Cu}$ matrix during cycling.

\section{Conclusion}

The interfacial adhesion of $\mathrm{W}$ and $\mathrm{Cu}$ is determined solely through mechanical interlocking. Interdiffusion and segregations experiment show that there are no interface reactions between $\mathrm{W}$ and $\mathrm{Cu}$ at the synthesis and operation temperatures. 
From the investigated interfacial concepts, the stepwise graded transition interface with additional heat treatment was found to achieve the highest interfacial shear strength.

Thermal cycling tests show that the thermal stability of the MMC can be assured by depositing a stepwise graded transition between $\mathrm{W}$ fibre and $\mathrm{Cu}$ matrix.

\section{Acknowledgement}

The authors would like to thank EADS (Ottobrunn) for performing the hot-isostatic pressing and OSRAM GmbH (Schwabmünchen) for providing the W fibres.

A part of this work has been performed within the framework of the Integrated European Project „ExtreMat“ (contract NMP-CT-2004-500253) with financial support by the European Community. It only reflects the view of the authors and the European Community is not liable for any use of the information contained therein. 


\section{References}

[1] H.D. Pacher, et al., J. Nucl. Mater. 241-243 (1997) 255.

[2] G. Federici, et al., Nuclear Fusion 41 (12R) (2001) 1987.

[3] D. Maisonnier, et al., EFDA Final Report of the European Fusion Power Plant Conceptual Study (PPCS), (2004).

[4] A.S. Kukushkin, et al., Fusion Eng. Design 65 (2003) 355.

[5] J.H. You, H. Bolt, J. Nucl. Mater. 305 (2002) 14.

[6] ASM International, Binary Alloy Phase Diagrams (1996)

[7] D.L. McDanels, NASA Technical Paper 2924 (1989)

[8] M. Mayer. SIMNRA user's guide, tech. rep. IPP 9/113, Technical report, Max-PlanckInstitut für Plasmaphysik, (1997)

[9] D.K. Shetty, J. Am. Ceram. Soc. 71 (1988) C-107.

[10] G. Rausch, B. Meier, G. Grathwohl, J. Eur. Ceram. Soc. 10 (1992) 229. 


\section{Figure captions}

Fig. 1: RBS spectra of $\mathrm{W}$ and $\mathrm{Cu}$ measured at room temperature, $500^{\circ} \mathrm{C}, 650^{\circ} \mathrm{C}, 800^{\circ} \mathrm{C}$ and $900^{\circ} \mathrm{C}$

Fig. 2: RBS spectra of unheated and heated $\left(650^{\circ} \mathrm{C}\right)$ stepwise graded transition from $100 \% \mathrm{~W}$ to $100 \%$ copper

Fig. 3: Comparison of interfacial shear strength td for the four investigated interfacial concepts

Fig. 4: SEM images of pulled fibres of single matrix coated samples with a) interfacial concept 1, b) interfacial concept 2, c) interfacial concept 3 and d) interfacial concept 4 Fig. 5: SEM images of the two investigated MMC discs after thermal cycling: a) and its magnification b) show the MMC with interfacial concept 2; c) and its magnification d) show the MMC with interfacial concept 3 


\section{Figures}

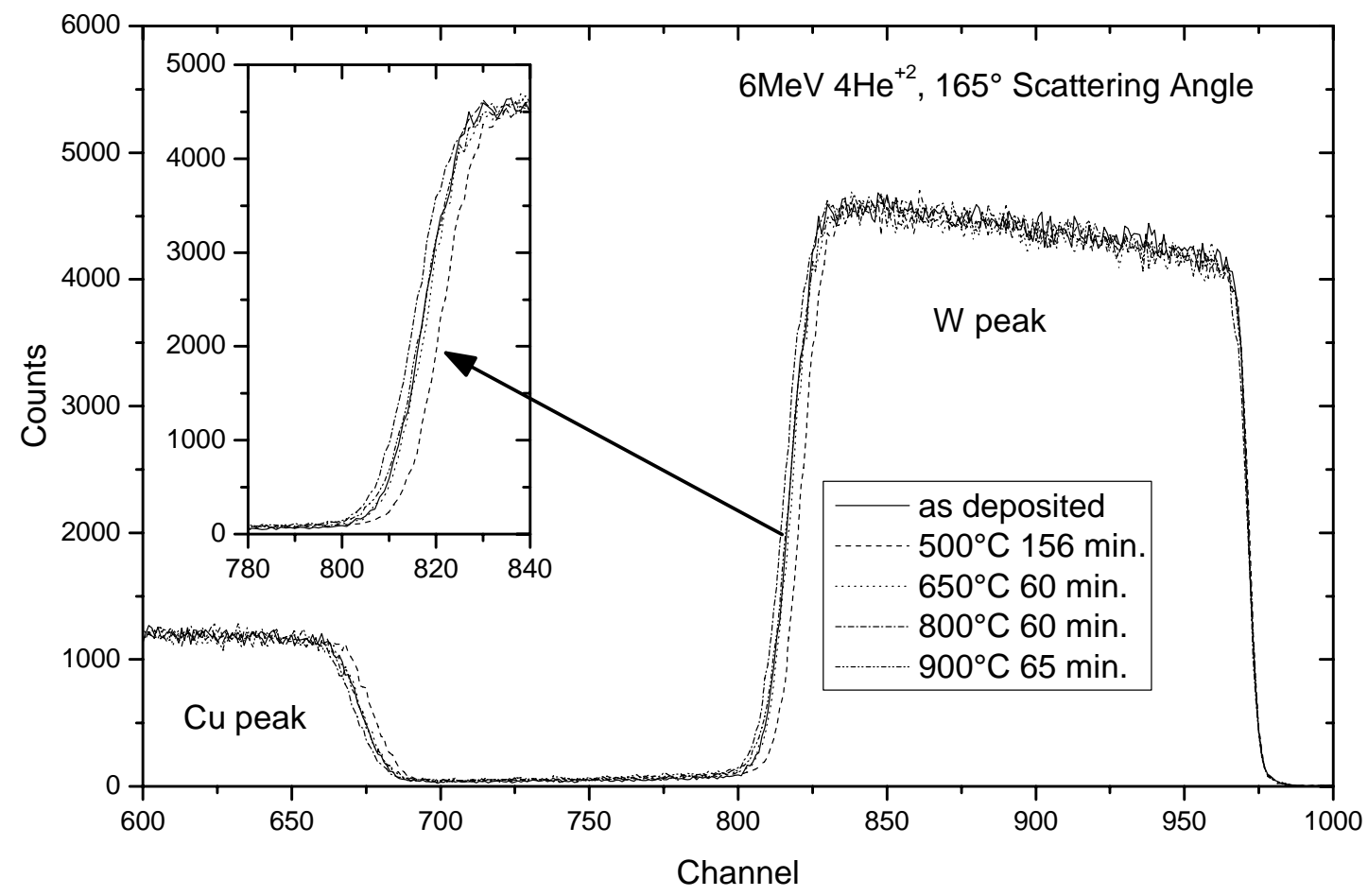

Fig. 1: RBS spectra of $\mathrm{W}$ and $\mathrm{Cu}$ measured at room temperature, $500^{\circ} \mathrm{C}, 650^{\circ} \mathrm{C}, 800^{\circ} \mathrm{C}$ and $900^{\circ} \mathrm{C}$ 


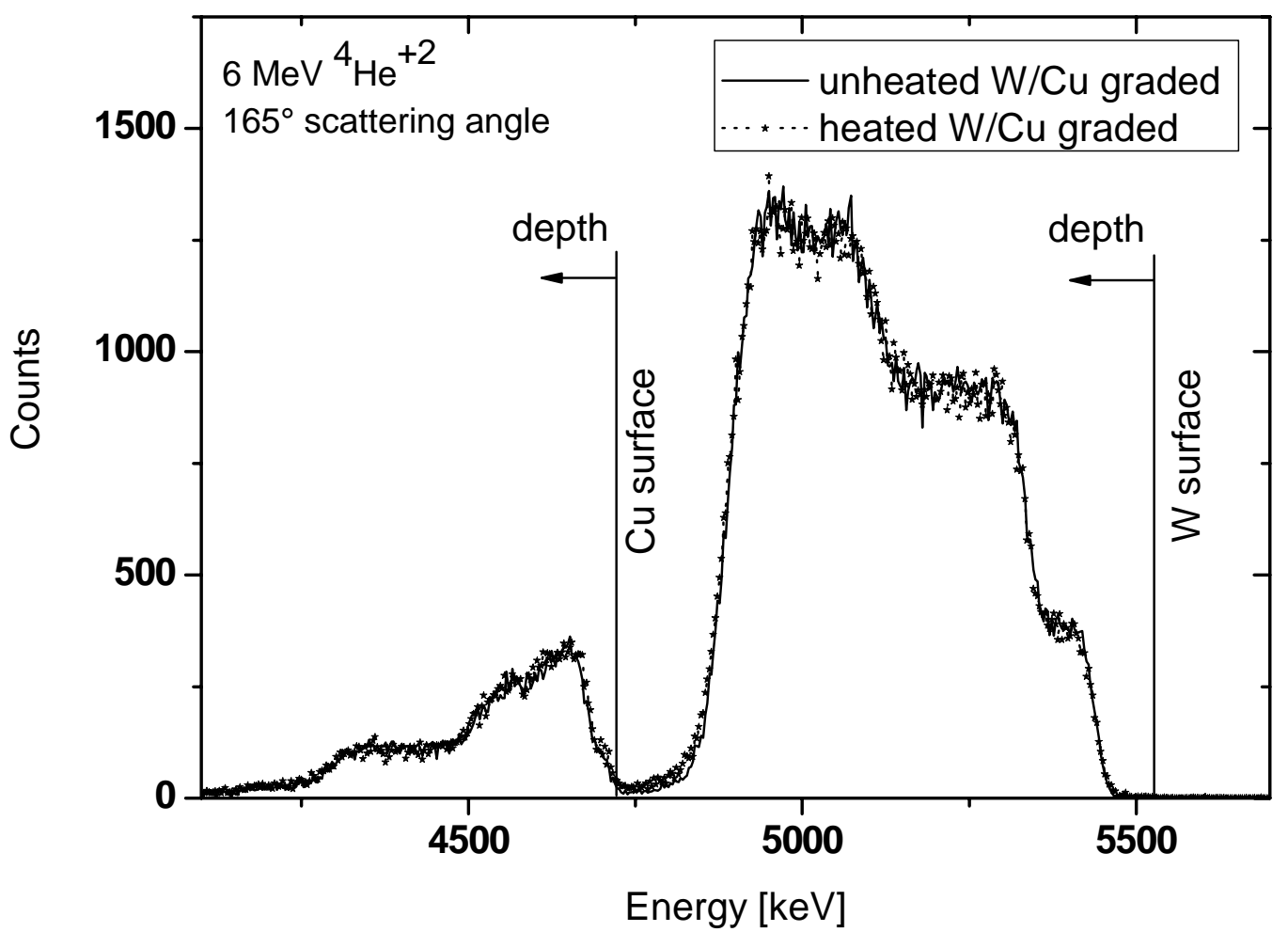

Fig. 2: RBS spectra of unheated and heated $\left(650^{\circ} \mathrm{C}\right)$ stepwise graded transition from $100 \% \mathrm{~W}$ to $100 \%$ copper 


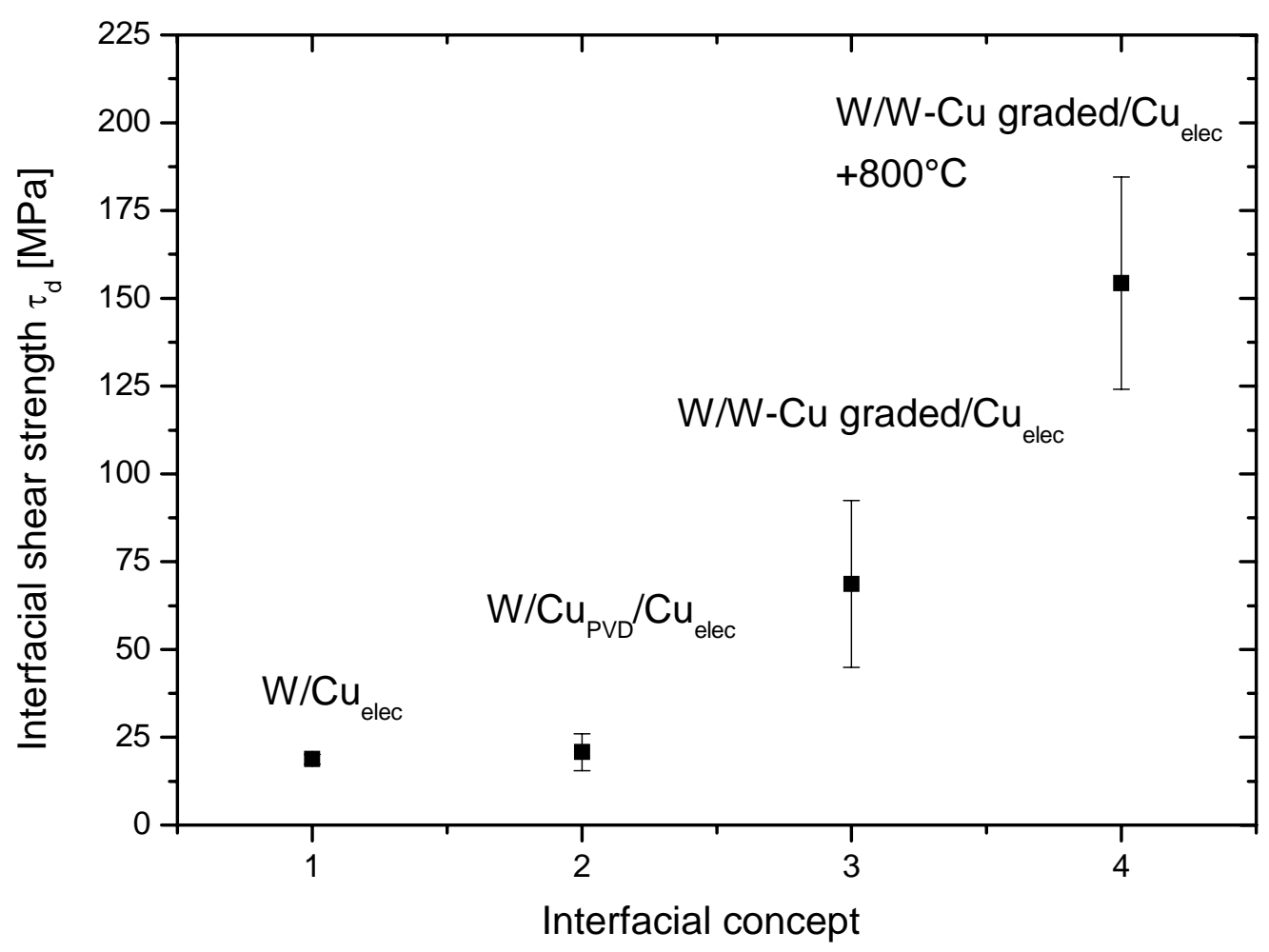

Fig. 3: Comparison of interfacial shear strength $\tau \mathrm{d}$ for the four investigated interfacial concepts 

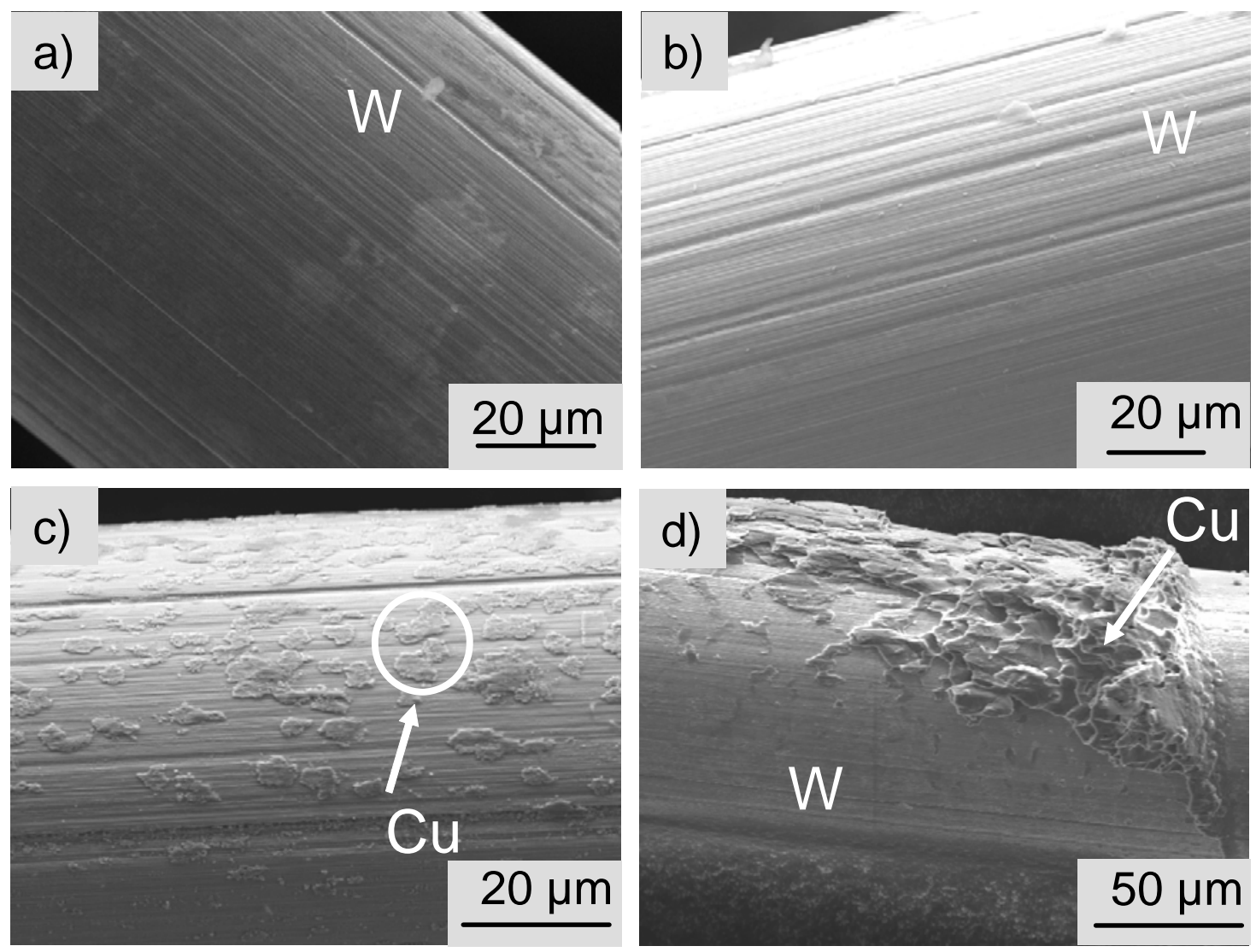

Fig. 4: SEM images of pulled fibres of single matrix coated samples with a) interfacial concept 1, b) interfacial concept 2 , c) interfacial concept 3 and d) interfacial concept 4 

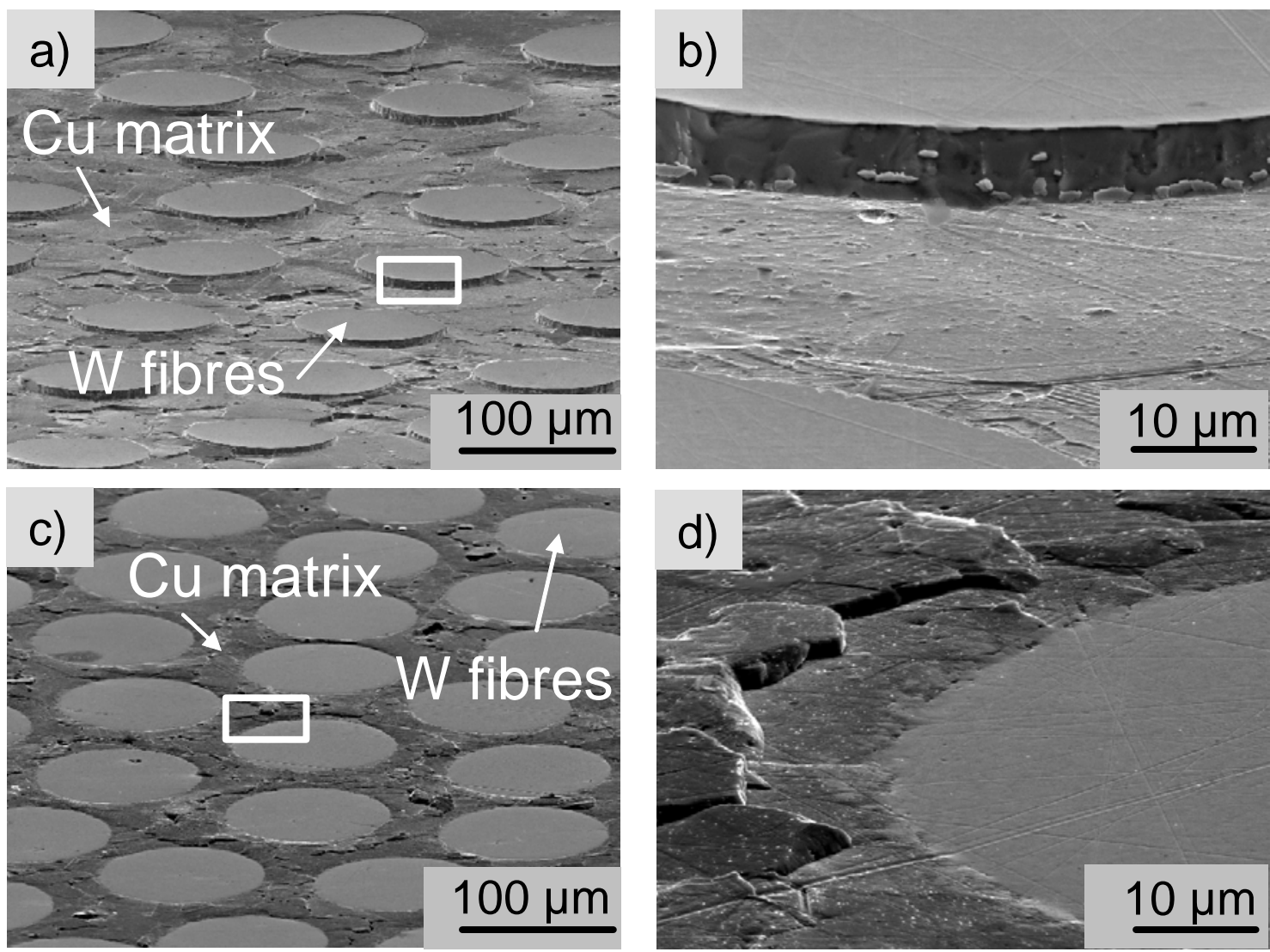

Fig. 5: SEM images of the two investigated MMC discs after thermal cycling: a) and its magnification b) show the MMC with interfacial concept 2; c) and its magnification d) show the MMC with interfacial concept 3 